\title{
Food and Drug Administration Action Against Homeopathic Teething Tablets Lacked Evidence Base
}

\author{
Burke Lennihan, RN, CCH
}

\section{Abstract}

A close examination of the incident reports to the Food and Drug Administration (FDA) regarding homeopathic teething tablets reveals a lack of evidence either for the FDA advisories regarding them or the media reports claiming that hundreds of infants were harmed soon after ingesting them. Many of the incident reports were requests for information from concerned parents, while the rest lacked a temporal association with ingestion or failed to rule out confounding medications or health conditions. The only other recent example of alleged harm from a homeopathic product was the case of Zicam $^{\circledR}$, withdrawn from the market after users reported loss of their sense of smell. Two views of Zicam are examined - that it was a supplement falsely labeled homeopathic or that it was an outlier among bona fide homeopathic medicines - neither of which would implicate the safety of homeopathic medicines in general. A recent New England Journal of Medicine perspectives piece is addressed: it calls for homeopathy to be regulated more stringently, as pharmaceuticals are. This article agrees that additional regulations and enforcement are needed. However, they should be limited to minor adjustments to make homeopathy more accessible to consumers and to minimize fraudulent products. This article asserts that homeopathy is already safer and can be more effective than pharmaceuticals, while current regulations of pharmaceuticals have failed to ensure their safety or effectiveness. The low risk-benefit ratio of homeopathy is asserted based on its minimal risk and its potential great benefit to consumers and the healthcare system as a whole, including cost savings, reducing antibiotic usage in humans and animals, and providing a rapid response to an epidemic. Finally, a proposed "new therapeutic order" is recommended in which safe holistic modalities such as homeopathy are used first, with drugs and surgery used only as a last resort.

C B Burke Lennihan 2018; Published by Mary Ann Liebert, Inc. This article is available under the Creative Commons License CC-BYNC (http://creativecommons.org/licenses/by-nc/4.0). This license permits non-commercial use, distribution and reproduction in any medium, provided the original work is properly cited. Permission only needs to be obtained for commercial use and can be done via RightsLink.
Keywords: homeopathy, FDA regulation, teething tablets, belladonna homeopathic

\section{Introduction}

The safety of homeopathic medicines has been called into question by Food and Drug Administration (FDA) actions against Zicam $^{\circledR}$, a product sold to treat colds, and teething tablets containing very dilute amounts of belladonna. In both cases, headlines in the media sensationalized the FDA action, exaggerating the dangers of the particular product and implying that all homeopathic medicines could be toxic. (An FDA action against a specific drug would not be headlined in the media as "Drugs Are Toxic, FDA Warns.") These examples will be discussed below, with a response to a New England Journal of Medicine (NEJM) perspectives piece calling for more stringent regulations on homeopathy. ${ }^{1}$

\section{Teething Tablets: The FDA Acted Prematurely with No Verified Proof of Harm}

The leading manufacturer of homeopathic teething tablets recalled them in April $2017^{2}$ at the request of the FDA, six months after it issued an advisory ${ }^{3}$ warning parents that they "may pose a risk to infants and children" without providing evidence of harm. The FDA advisories against teething tablets cited hundreds of consumer claims of harm and 10 deaths. A report from STAT, an online news agency specializing in health news, claimed that the FDA collected "reports that the tablets had caused seizures and other severe complications in hundreds of infants ... who had been given the product, according to a STAT investigation," referencing an earlier STAT report, ${ }^{4}$ but not based directly on the FDA reports. ${ }^{5}$

A close examination of these reports reveals that many or even most of them are not plausible, and none were verified. Correlation does not prove causation; babies have febrile seizures, and thousands of them die every year from sudden infant death syndrome (SIDS)* in the same age range as teething. ${ }^{6}$ In

*The estimate ranges from 2,000 to 5,000 per year, depending on how SIDS is defined and diagnosed, which varies from state to state. ${ }^{6}$ 
fact, a group of physicians conducted a relative risk-ratio analysis on the FDA reports and concluded that the incidence of seizures and deaths among these babies was no greater than in the same age range in the general population. ${ }^{7}$

The FDA warning - advising parents to be on the alert for common symptoms in infants such as drowsiness, agitation, and constipation-generated requests for information from alarmed parents who otherwise would not have associated them with teething tablets. These requests were counted by the FDA as "incident reports," along with bona fide reports of harm. Social media spread the alarm; one mother posted on Facebook that she had read about belladonna on Wikipedia and found it to be "the most toxic plant in the Western hemisphere" (Case 10547547). Physicians compounded the fear: in one case, the physician "screamed" at the mother of a child with a rash, upon seeing belladonna in the ingredients of the teething tablets, because the child "could have gone into cardiac arrest and died" (Case 7668156).

Types of reports with questionable causality include the following FDA case numbers as examples:

- Reports that a physician "determined" or "confirmed" that a child's symptoms were caused by the belladonna (7664990): physicians are not trained in homeopathic dilutions and would assume a connection based on fullstrength belladonna toxicity. A physician would have needed access to specialized lab equipment to "determine" that there was enough belladonna to cause the seizure.

- Requests for information, such as from the mother whose baby's heart murmur was not discovered until several months after birth, wondering if the teething tablets might have caused it (8733145).

- Reports unrelated temporarily to ingestion, ranging from the infant whose cheeks flushed the day after a teething tablet (766284) to the 10-year-old boy and his five-yearold sister, both with developmental delays including lack of speech, whose mother blamed teething tablets given when they were six months old (10542735).

- Many reports involve other health conditions or medications the baby is on, such as the baby with constipation who is also on lansoprazole, which has constipation as a common side effect ${ }^{8}$ (7665383).

- Reports of seizures involving babies who simultaneously had a fever (which can often happen with teething); in some cases, the physician clearly diagnosed a febrile seizure $(7665414,7667750)$ or viral illness $(7673718)$.

- Reports of harm from another homeopathic brand not containing belladonna (7966799) or a non-homeopathic brand containing benzocaine, which can have its own serious side effects (7739701).

- Apparent errors such as the 40-year-old man on bupropion, atenolol, and quetiapine in addition to a dozen supplements such as "Ripped Freak" and "Hydrashred" as well as, inexplicably, Hyland's teething tablets, who died of a drug overdose (9681215); or the 33-year-old alcoholic who had been stabbed in the abdomen and supposedly was taking teething tablets (8291771); or the 65-year-old woman taking Hydroxycut ${ }^{\circledR}$ for weight loss, erroneously listed as Hyland's teething tablets on the summary sheet (perhaps due to an autofill error on the form: $8291776=8478591$, one of many duplicate reports).

This leaves several dozen reports in which causality is possible but not provable. When an infant dies of acetaminophen overdose, blood levels of acetaminophen can be measured as well as liver enzymes, which in one recent case were 200 times higher than normal. ${ }^{9}$ In none of the 10 cases of reported death from belladonna toxicity were liver enzymes measured, nor was the level of belladonna alkaloids in the blood or in the teething tablets.

The most common symptoms reported to the FDA were fever, rash, and seizures, all fairly common in infants. The reports were typically not verified; in a few cases, follow-up phone calls were made by the manufacturer, but not returned, making it more difficult to determine causality. The reports of death included one infant with a fever whose mother could not even remember if she had given the teething tablets; the cause of death was diagnosed as SIDS (9282659). Another infant was given her first-ever dose of a teething tablet, put to bed with a bottle, and found dead in the morning in a puddle of vomit (10723317). The most likely explanation is that she had infant reflux and aspirated some of the vomit. These cases are among the deaths attributed to teething tablets, although the causality is unlikely. In no case is the causality proven.

Evidence against teething tablets causing seizures and death include:

- The FDA carefully regulates the threshold for dilution of toxic ingredients, just as it does with conventional drugs, such as the level of botulism toxin in Botox ${ }^{\circledR}$ or the level of belladonna alkaloids in pupil-dilation drugs. For the small percentage of homeopathic medicines derived from a medicinal substance that would be toxic if administered full strength, the FDA requires a substantial margin of error $^{10}$ (in the case of belladonna, a 1,000-fold margin of error).

- The FDA's spectroscopic analysis of 1,000 bottles of the teething tablets revealed a 10 -fold variation in the amount of belladonna, the potentially toxic ingredient, but even the highest concentration was 1,000 times less than the safe amount - meaning that a baby would have to swallow 1,000 tablets of the highest concentration at one time.

- Hyland's itself does a spectrographic analysis of every batch of teething tablets to ensure safe dilution levels.

- HealthCanada, the Canadian equivalent of the FDA, issued an advisory immediately after the FDA's, stating that it would take no action because it had received no complaints of belladonna toxicity (only four verified safety claims in 11 years) ${ }^{11}$ and considered the tablets safe. ${ }^{12}$ Hyland's Teething Tablets (a popular brand in Canada) are manufactured in the United States.

There are no reports of harm from young children swallowing an entire bottle of 135 teething tablets, which they are 
apt to do because the tablets consist primarily of sugar. The FDA case reports include one of a toddler ingesting about 50 tablets with no side effects (7667724). The FDA advisory warning parents using teething tablets to be on the alert for common infant behaviors such as drowsiness and restlessness received media attention out of proportion to the amount of evidence, which the FDA admitted it had not yet begun to examine. The resulting media attention amplified the false impression that homeopathy is harmful, both among the public and among healthcare professionals.

\section{Zicam: A Supplement Incorrectly Marketed as a Homeopathic?}

The only other example in recent years of an FDA action based on possible harm from a homeopathic remedy was its 2009 advisory against Zicam. Homeopathic medicines are allowed to make label claims, that is, claims on the label that they are effective against a particular health condition - in fact, they are required to do so under FDA regulations - whereas supplements are not allowed to claim such effectiveness. ${ }^{11}$ Zicam made a label claim (that it was effective against colds) based on its homeopathic production method, but it contained a substantial amount of zinc and therefore acted as a supplement. ${ }^{13}$ Whether it should have been regulated as a supplement or as a homeopathic medicine will be examined below.

While the FDA has a safety threshold for dilutions of toxic starting substances such as belladonna, it does not restrict the dilution level of nontoxic substances such as zinc, the active ingredient in Zicam. Zinc is an essential mineral, sold as a supplement and nontoxic when taken orally (except in megadoses). It has been known to cause anosmia (loss of the sense of smell) in a small percentage of users; $1 \%$ of users in one study. ${ }^{14}$ The manufacturers of Zicam used a homeopathic dilution process - but only in the first step of the process, a $10 \%$ solution called a $1 \times$ potency. This left measurable amounts of zinc, enough to cause anosmia in a small percentage of users.

In addition, Zicam used a route of administration (intranasal, applied directly to the nose) that had never before been used for homeopathy. (Many other homeopathic products use this 10\% dilution of a nontoxic medicinal substance without causing side effects; apparently Zicam caused anosmia by an unfortunate combination of the unique delivery route and a nontoxic medicinal substance causing a side effect in that specific tissue.) By providing full-strength zinc applied directly to the nose, the alleged benefits of Zicam as well as its infrequent side effect were both based on its action as a supplement, not its action as a homeopathic medicine. In fact, Zincum (homeopathic zinc) is not known as a medicine for colds. ${ }^{15-17}$

So was Zicam a bona fide homeopathic medicine or a supplement masquerading as homeopathic in order to make a label claim? Both views are possible. It was technically correct to call it a homeopathic medicine because it followed FDA regulations, but its mechanism of action was as a supplement rather than a homeopathic medicine (more about homeopathy's mechanism of action below). Either way, it is an outlier among homeopathic medicines and cannot be used to imply toxicity for homeopathy overall.

Unfortunately, the media coverage did exactly that. The coverage was disproportionate to the problem (no one died). An Associated Press (AP) article that was picked up by media around the world implied that homeopathy is toxic, based on this incident and the misleading information that homeopathic medicines are made from alcohol. ${ }^{18}$ The article implied that the alcohol content can cause toxicity without any FDA evidence to support the claim.

In fact, the AP article seemed designed in advance to promote the idea that homeopathy is toxic. The interviews for the article were conducted months before the Zicam recall, with the journalist privy to an FDA action that had not yet been made public, and were narrowly focused on the concept of alcohol content. This author was the professional homeopath interviewed for the article, providing extensive information about research on homeopathy and its clinical effectiveness, none of which was included in the article. The reporter asked multiple questions about the alcohol content and was repeatedly told that homeopathic medicines do not contain alcohol, with rare exceptions. Yet, the article focused on the purported dangers of the alcohol content. A pharmacy safety expert from Harvard Medical School was quoted as saying, "Very often, the only active ingredient is alcohol, and patients don't know that, and they get a buzz on. The therapeutic effect is no greater or less than a martini." ${ }^{19}$ This unfounded assessment could best be explained by the journalist providing incorrect information, then asking a leading question.

The Zicam incident may provide a better example of biased media coverage of homeopathy than of danger from homeopathy. The entire article seemed designed to discredit homeopathy - it was published in major newspapers around the world under headlines such as "Homeopathy Not Without Harmful Side Effects." Yet, it cited only two examples, which were inconsistent: the harm from Zicam was blamed on zinc rather than on alcohol, and no examples of harm from alcohol were provided.

\section{Call for Increased Regulation of Homeopathy}

A NEJM perspectives article has called for more stringent regulation of homeopathy, ${ }^{1}$ based on the FDA recall of Zicam (the article was published before the FDA action against Hyland's Teething Tablets). Homeopathy is regulated by the FDA under its own regulatory board, the Homeopathic Pharmacopoeia of the United States (HPUS; a parallel compendium to the United States Pharmacopoeia). It achieved this status as part of the Food, Drug, and Cosmetics Act of 1938 due to the efforts of a senator from New York, a homeopathic physician elected based on his success as New York City's public-health commissioner using homeopathy to stem the Spanish flu epidemic. ${ }^{19}$ Homeopathic medicines have NDA numbers like drugs, and almost all have over-the-counter (OTC) status. 
(A small percentage are available only by prescription because their starting substance is a prescription drug or illegal substance, even when it is only present as non-toxic nanoparticles.)

The regulation of homeopathy is closer to that of conventional drugs than to that of supplements and herbs. ${ }^{11}$ As with conventional drugs, complaints to the FDA can trigger an FDA advisory or recall. The FDA prioritizes whether and when to act on these complaints. To put this in context, it has not yet acted on the Acute Liver Failure Study Group's 2004 challenge to acetaminophen's OTC status based on more than 450 deaths and more than 55,000 emergency room visits per year due to acetaminophen toxicity. ${ }^{20}$

The current regulation of homeopathy is appropriate, given homeopathy's overall safety and effectiveness, addressed in detail below. It assigns the regulation to those professionally trained in homeopathy rather than to experts in conventional medicine, because homeopathy operates within a different therapeutic paradigm requiring a different approach to regulation.

The NEJM perspectives piece recommends that homeopathic medicines should be required to prove their safety and efficacy via randomized controlled trials (RCTs) as prescription drugs are required to do. However, this system has failed to protect the consumer from conventional drugs, which cause more than 100,000 deaths per year, compared to a dozen deaths per decade - none of them verified - that are ascribed to homeopathy. Nor is it sufficient to ensure efficacy of drugs, as evidenced by fluoxetine recently revealed to be no more effective than placebo for mild depression yet which is still on the market. ${ }^{21}$ The British National Health Service has estimated that only $13 \%$ of its treatments (drugs and others) are beneficial, while $50 \%$ are harmful or of unknown effectiveness ( $4 \%$ and $46 \%$, respectively). Furthermore, drugs are often prescribed for conditions for which they are not proven: this "off-label use" constituted $21 \%$ of prescriptions in a 2006 study, with $73 \%$ of this type of prescription having poor or no scientific support. ${ }^{22,23}$ A regulatory system inadequate for prescription drugs is unlikely to improve the safety and efficacy of homeopathic medicines; homeopathic medicines are already safer and in some cases more effective than pharmaceuticals, as will be discussed later in this article.

Instead, homeopathic medicines are vetted through a process that includes provings, a testing method appropriate for homeopathy's therapeutic paradigm, as part of their inclusion in the HPUS. "The difference [in the approval process for homeopathic medicines versus conventional drugs] reflects ... the necessity for data collection techniques that are specific to the therapy ... data collection from provings are much more useful [than RCTs] in developing a more complete symptom picture that offers insight into clinical effectiveness." 11

The RCT standard is more appropriate for a system of medicine based on introducing a single foreign molecule into the body, whereas homeopathy's mechanism of action is based on electromagnetic signaling, thermoluminescence, or other form of information transfer, according to research in materials science and ultra-high dilution physics. ${ }^{\dagger 24-28}$ It is considered the gold standard, at the top of the hierarchy of evidence in medicine, but the RCT format is increasingly being questioned by experts from within conventional medicine. Professor Sir Michael Rawlins, in the distinguished Harveian lecture to the Royal College of Physicians of London in 2008, provides a detailed analysis of the limitations of the RCT model and the value of other forms of research design: "Hierarchies place RCTs on an undeserved pedestal for ... although the technique has advantages it also has significant disadvantages." 29

The RCT standard is also being questioned because results can be skewed to fit the desired outcome of the funding source. ${ }^{30}$ Government agencies such as the Agency for Healthcare Research and Quality, ${ }^{31}$ the Patient-Centered Outcomes Research Institute, ${ }^{32}$ and the Office of Research Integrity ${ }^{33}$ are currently questioning the value of RCTs or requiring other measures such as real-world outcome studies.

Natural systems of healing (such as naturopathy and acupuncture as well as homeopathy) can best be studied via large-scale outcome studies such as those being done on homeopathy in Europe. ${ }^{34-36}$ The RCT model of pinpointing the action of one drug for one specific condition is cumbersome for the use of homeopathy in chronic diseases because homeopathy is individualized to the patient in these situations (thus 10 patients with the same diagnosis are likely to receive 10 different homeopathic medicines). However, the RCT model can work in acute conditions in which one particular homeopathic medicine is of almost universal effectiveness, such as Nux vomica to help addicts with post-withdrawal symptoms, ${ }^{37}$ or the use of homeopathy for an epidemic as described below (with placebo-controlled trials limited by ethical considerations).

\section{Homeopathy's Risk-Benefit Ratio}

In this era of spiraling healthcare costs ${ }^{38}$ and the rise of antibiotic-resistant microbes, ${ }^{39}$ homeopathy offers many benefits to individual consumers and to the healthcare system at large.

\section{Safety}

Homeopathy has been safely used in the United States and around the world for 200 years. The two examples cited above are the only examples of FDA actions based on safety concerns in recent years. A report by the Rocky Mountain Poison Control Center to the FDA's public hearings on homeopathy in 2015 cited only two deaths from homeopathy in a decade, ${ }^{40}$ and even those deaths were not verified: the poison control

\footnotetext{
†Readers interested in homeopathy's mechanism of action but who find the physics in these studies daunting are encouraged to view Dr. Bell's explanation of her research, "Pursuing the Biological Basis of Homeopathic Remedy Response," at https://www.youtube $. \operatorname{com} /$ watch?v=0_sQjsKv8ic\& $=3347 \mathrm{~s}$
} 
center does not investigate the product being reported, and consumers often misuse the word "homeopathic" believing it to be synonymous with "herbal" or "holistic."

Studies from Europe, where homeopathy is part of the healthcare system in most countries, document its relative lack of side effects. For example, a review of Germany's drug safety database on more than 300 million doses of homeopathic medicines (and other similarly prepared medicines) revealed only 46 case reports considered "serious," mostly consisting of redness, rashes, and swelling (most likely due to the medicines being delivered by injection, a method not used in the United States). ${ }^{41}$ The lack of side effects has the benefit of increasing patient compliance, as in a study comparing homeopathy to fluoxetine for depression (showing comparable benefits, but more patients on fluoxetine dropping out of the study due to "troublesome side effects"). ${ }^{42}$

The comparison to conventional medications will be familiar to readers: as of 2011, an estimated 81 million hospitalized Americans had experienced a serious adverse reaction to a prescription drug each year, and an estimated 128,000 per year had died as a result. ${ }^{43}$ Only 1 in 12 new drugs provides a clinical advantage over existing ones for the same condition, "while the proportion with serious harms has gone up from 1 in 5 towards 1 in 3." 44 Off-label prescribing (prescribing a drug for a condition for which it has not been tested) makes the balance even worse, with $75 \%$ of off-label prescribing not "supported by sound evidence." 44

\section{Effectiveness}

Randomized controlled studies comparing homeopathic medicines to a leading drug for a particular condition are rare. In addition to the just-cited study on fluoxetine, a homeopathic combination remedy for vertigo in another study was comparable in effectiveness to betahistine. ${ }^{45}$

Large-scale outcomes studies, comparing the overall results from homeopathic versus conventional treatment, have been conducted more frequently and have shown better results because they have greater model validity for homeopathy. A French study showed that children treated by a homeopathic physician for URIs were significantly more likely to have a positive result of treatment compared to children treated with an antibiotic; they also had fewer complications, better quality of life, and their parents needed fewer family sick-leave days. ${ }^{46}$ An international primary care outcomes study comparing homeopathic and conventional treatment for acute respiratory and ear complaints found that children treated homeopathically experienced complete recovery or major improvement at a significantly faster rate than children undergoing conventional care. ${ }^{47}$ A study seeking to replicate this study showed that onset of improvement was faster in the homeopathic group, and adverse drug reactions occurred more frequently in adults in the conventional group. ${ }^{48}$

Homeopathic treatment was compared to standard of care in a prospective observational study of German children with otitis media: the homeopathically treated group recovered more quickly, and fewer than $5 \%$ ended up receiving antibiotics. $^{49}$

\section{Cost Savings}

Homeopathic medicines cost as little as one cent per dose, providing immediate cost savings and also long-term benefits by reducing the influence of pharmaceutical profits on medical doctors and medical decision making. Long-term studies on patients who choose homeopathic versus conventional providers indicate that the former tend to recover more quickly from chronic illnesses and require less medication over time. ${ }^{35,50}$ The Swiss government five-year study of homeopathy included a cost-effectiveness study showing a $15 \%$ reduction in the cost of claims made against its mandatory health insurance. ${ }^{51}$ A Brazilian study indicated that even though homeopathic physicians ordered fewer tests than conventional family health doctors, they were able to resolve patients' problems. ${ }^{52}$

\section{Replacing Antibiotics to Stem the Rise of Antibiotic-Resistant Microbes}

A study on a homeopathic cough syrup with or without additional antibiotics demonstrated that the antibiotics added no therapeutic value yet added unwanted side effects ${ }^{53}$; coughs, although often viral in nature, are a leading reason why antibiotics are prescribed in the United States. A study in France, where people can choose a conventional or homeopathic pediatrician or primary-care doctor, comparing children offered homeopathic or conventional treatment for recurrent colds found that the former had fewer recurrences, fewer complications, and better quality of life, and the parents needed fewer sick-leave days. ${ }^{47} \mathrm{~A}$ recent double-blind placebo-controlled trial of homeopathy versus conventional treatment for acute ear infections showed that the homeopathy group recovered faster and had a much lower rate of antibiotic prescriptions $(0 \%$ vs. $97.5 \%) .{ }^{54}$

Adjunctive homeopathic treatment has even been shown to be beneficial for accelerating resolution of severe, potentially fatal sepsis in a research study in the intensive care unit (ICU). ${ }^{55}$ In the same ICU at the University of Vienna Hospital, homeopathy was used to revive terminal patients for whom conventional medicine had nothing more to offer; before-andafter labs and diagnostic imaging document their revival by homeopathy. ${ }^{56}$

Animal studies have demonstrated homeopathy's effectiveness compared to antibiotics, for example in preventing diarrhea and kennel cough in piglets, ${ }^{57,58}$ and mastitis in dairy cows. ${ }^{59}$

\section{Quelling Epidemics}

Homeopathic medicines can be immediately effective in epidemics, obviating the need for slow and costly drug development. ${ }^{60}$ Meticulous records kept by public-health officials,

\footnotetext{
FFor example, a homeopathic remedy kit for home use containing 100 tubes (each with about 1,000 pellets) is available online from several homeopathic manufacturers for $\$ 225$ or $\$ 2.25$ per tube, with one dose typically being two pellets.
} 
hospitals, and physicians provide historical evidence that homeopathy is effective in epidemics such as cholera for which conventional medicine still lacks effective treatment. ${ }^{61,62}$ In the great Spanish Flu pandemic following World War I, tens of millions of people died worldwide - except those treated with homeopathy, who had only a $1 \%$ mortality rate. ${ }^{63}$

Recent examples of the effectiveness of homeopathic medicines against epidemics include the annual leptospirosis epidemic in Cuba, in which millions of people have been protected more effectively than with the previously used pharmaceuticals. ${ }^{64}$ One year when the drugs were in short supply, homeopathic prevention used with 2.3 million people stopped the epidemic in its tracks. The results could be compared both to previous years and to the rest of the island where the drugs were used: the intervention was "strongly associated with a drastic reduction of disease incidence resulting in complete control of the epidemic." The protective effect continued into the following year: a $84 \%$ reduction in leptospirosis in treated areas compared to a $22 \%$ increase in untreated areas. A careful reanalysis was able to eliminate possible confounders such as variance in rainfall. ${ }^{65}$

A meningococcal epidemic in Brazil in 1998 provided the opportunity to compare those protected with a homeopathic medicine against those who were not. In this governmentfunded study of nearly 90,000 people, there were four cases of meningococcal disease among those protected compared to 58 cases that would have been expected, based on the rate among the unprotected cohort. This represented a $95 \%$ protection rate in the first six months and a $91 \%$ protection rate over the year. ${ }^{66}$

Laboratory studies also indicate homeopathy's effectiveness against epidemic diseases such as malaria ${ }^{67}$ and Japanese encephalitis $^{68}$; in the malaria study, homeopathic treatment was more effective than pyrimethamine, the standard of care.

\section{Obstacles to Inclusion}

Physicians and other healthcare practitioners may well question these asserted benefits of homeopathy, given its exclusion from our healthcare system and general lack of familiarity with it in the United States. Or they might well ask why homeopathy is not a part of mainstream medicine here as it is in Russia, India, and many countries in Europe and South America. In France, for example, 95\% of primary-care physicians and pediatricians prescribe homeopathic medicines ${ }^{69}$; France has the best healthcare in the world, according to the World Health Organization. ${ }^{70}$ India has hundreds of homeopathic hospitals, several hundred thousand professional homeopaths, and 100 million people who depend on homeopathy as their sole method of healthcare. ${ }^{71}$

Obstacles to the acceptance of homeopathy include:

- The myth that it cannot possibly work because there is nothing in it. Recent research on homeopathic solutions using transmission electron microscopy shows the presence of nanoparticles of the medicinal sub- stance. ${ }^{28}$ A number of possible mechanisms of action are emerging through the research in materials science and ultra-high dilution physics cited earlier.

- The myth that homeopathy is unproven. In fact, there are more than 1,000 research studies documenting the effectiveness of homeopathy available in an online database; 352 of them were published in peer-reviewed journals, and 198 of those were RCTs. ${ }^{72}$ Of 22 metaanalyses, 20 showed at least a trend in favor of homeopathy, according to the Swiss government. ${ }^{73} \mathrm{~A}$ Swiss "Health Technology Assessment" committee spent five years reviewing all the research, as well as conducting its own research on its citizens' use of homeopathy versus conventional medicine, and decided as a result to continue covering it as part of their national health insurance. ${ }^{74}$ The committee's findings were published in a 300-page book. ${ }^{51}$

- The myth of evidence-based medicine. The myth that conventional medicine is evidence based while holistic modalities are not is belied by the review in the British Medical Journal: among thousands of common medical treatments, the research showed only $13 \%$ were found to be beneficial and 23\% likely to be beneficial, while $4 \%$ were likely to be harmful or ineffective and $46 \%$ were unknown in their effectiveness. ${ }^{75}$

- Lack of funding for research on homeopathy. Because homeopathic medicines are not patentable, there is insufficient profit generated to support research by homeopathic manufacturers in the United States. Conventional pharmaceutical companies spend more than $\$ 100$ billion dollars a year on research, ${ }^{76}$ while there is little or no funding for research on homeopathy. Homeopathy needs substantial additional research funds for large-scale trials and replications of its trials, areas in which homeopathic research is weak.

- The pharmaceutical industry's influence on the media, based on the billions of dollars it spends on direct-toconsumer advertising.

- Media coverage focused on negative press about homeopathy. Certain studies seem deliberately designed to discredit homeopathy, as they were co-authored by opponents of homeopathy and relied on heavily manipulated statistics. They have received disproportionate media coverage, both for the general public and for physicians. In fact, they are the only widely cited studies on homeopathy. The 2005, Shang et al.'s study used arbitrary and undisclosed standards to reduce 110 research trials to just eight described as "higher quality" and to conclude that homeopathy works no better than placebo. ${ }^{77}$ However, including all 21 studies identified in the study as higher quality would have shown that homeopathy works better than placebo. ${ }^{78}$ An independent statistics expert cited its "flawed statistical methods." 79 A more recent study on 151 placebo-controlled RCTs showed homeopathy is 1.5-2.0 times more likely to work than placebo. ${ }^{80}$ 
Perhaps even more damaging was the 2015 Australia commission report, widely perceived to represent an official position of the Australian government against homeopathy, although the government continues to provide insurance coverage for homeopathy. Proposed by an anti-homeopathy lobbying group, a review committee chaired by a known skeptic of homeopathy used arbitrary standards (such as requiring that studies have more than 150 subjects and a perfect quality score) to conclude that "there are no health conditions for which there is reliable evidence that homeopathy is effective." 81 A detailed rebuttal has been submitted to Australia's Ombudsman to have the report retracted.$^{82}$ In the meantime, "Homeopathy is bunk, study says" has been a typical headline. ${ }^{83}$

None of the positive studies about homeopathy are mentioned in the media, nor are the detailed responses to the negative studies. The message of the Shang study ("homeopathy is no better than placebo) and of the Australia report ("homeopathy is proven not to work for any condition") continue to be repeated in the popular press and specialized media for healthcare professionals, just as the FDA action against teething tablets has received widespread coverage and physicians' analysis of its lack of evidence has received none.

- The pharmaceutical industry's influence on physicians' access to information: the pharmaceutical industry underwriting continuing medical education conferences, drug reps who visit doctors' offices reporting the latest research favorable to their products, advertising in medical journals, and even the content of the journals. $^{31}$

- Publication bias against homeopathy. Studies submitted to peer-reviewed journals are routinely rejected when they include the word "homeopathy" and accepted when submitted to another journal with the word "homeopathy" deleted. ${ }^{84}$ The study on homeopathy's effectiveness in the leptospirosis epidemic in Cuba was rejected by journals that had previously accepted articles by the same authors. ${ }^{66}$

\section{Recommendations for Increased Regulation}

The author agrees with the authors of the NEJM perspectives piece that homeopathy needs additional regulation. However, homeopathy's low risk of harm and great potential benefit indicate that the existing regulatory system should stay intact, with only minor changes to make it more user-friendly for consumers and to prevent non-homeopathic products fraudulently posing as homeopathic. Specifically:

- Single or individual (not combination) homeopathic medicines are currently required by the FDA to carry an indication for use on their label. These are confusing for consumers, as each homeopathic medicine can treat more than one condition, and each condition could be treated by more than one medicine. Lachesis, for example, may state "hot flashes" as its indication for use, a deterrent to the male consumer seeking to treat his sore throat, for which Lachesis is also an effective medicine. Omitting this mandatory indication for use would make homeopathy less confusing for consumers.

- Combination products containing homeopathic medicines and supplements should not be labeled as homeopathic, nor should they be allowed to make label claims as if they were purely homeopathic: this existing regulation needs to be strictly enforced.

- Combination products consisting solely of homeopathic medicines should continue to be allowed label claims consistent with the HPUS indications for at least one of the ingredients.

- Homeopathic products available OTC should not carry a label claim for a chronic condition that requires medical supervision. Current FDA regulations already prohibit this: homeopathic products are only categorized as OTC if appropriate for self-treatment. However, this regulation is rarely enforced, and these products are widely available online and in stores. They need to carry a warning label such as "Use only under medical supervision as an adjunct to conventional medical treatment," given the difficulty with strict enforcement of the existing regulation.

\section{Conclusion: Need for a New Therapeutic Order}

A new therapeutic order is being proposed by a physician ${ }^{85}$ and a group of naturopaths. ${ }^{86}$ While differing in the details, both propose inverting the current triage of healthcare for chronic illness in which holistic modalities are resorted to only after conventional drugs and surgery have failed. Instead, these authors propose a "first do no harm" order of treatment interventions: lifestyle modifications including changes in diet, exercise, and stress reduction, followed by energy-based modalities such as acupuncture and homeopathy. The next step, if necessary, would be the high potency supplements of naturopathy and functional medicine, followed by drugs and surgery only as a last resort. These authors contend that upending the current triage is necessary to reform our current healthcare system, which is by far the most expensive in the world yet provides the worst results among high-income countries. ${ }^{87}$ Both proposals include homeopathy high on the priority list. It is hoped that this article has dispelled any concerns about the safety of homeopathy or the need for further regulation.

\section{Acknowledgments}

The author wishes to thank Dana Ullman, $\mathrm{MPH}, \mathrm{CCH}$, for his ongoing labors in collecting and evaluating the worldwide research on homeopathy. 


\section{To Contact Burke Lennihan}

Burke Lennihan, RN, CCH

777 Concord Ave., Suite 301

Cambridge, MA 02138

E-mail: blennihan@alumni.harvard.edu

\section{Author Disclosure Statement}

No competing financial interests exist.

\section{References}

1. Podolsky S, Kesselheim AS. Regulating homeopathic products: A century of dilute interest. N Engl J Med 2016;374:201-203.

2. Homeopathy company launches nationwide recall of tablets blamed for infant seizures. STAT, April 13, 2017. Online document at: www .statnews.com/2017/04/13/homeopathy-tablets-recall/ Accessed April 27, 2017.

3. FDA warns against use of homeopathic teething tablets and gels. FDA News Release, September 30, 2016. Online document at: www.fda.gov/ NewsEvents/Newsroom/PressAnnouncements/ucm523468.htm Accessed May 7, 2017.

4. Kaplan S. Homeopathic remedies harmed hundreds of babies, families say, as FDA investigated for years. STAT, February 21, 2017. Online document at: www.statnews.com/2017/02/21/hylands-homeopathic-teething-fda/ Accessed May 8, 2017.

5. FDA Adverse Event Reporting System (FAERS). FOIA Case Report Information, November 4, 2016. Online document at: www.fda.gov/downloads/ drugs/guidancecomplianceregulatoryinformation/cderfoiaelectronicreadingroom/ ucm548711.pdf Accessed April 20, 2017.

6. Lafrance A. How many babies really die of SIDS? Understanding Sudden Infant Death Syndrome. The Atlantic, June 2, 2016.

7. Whitmont R. President's Letter, American Institute of Homeopathy. Online document at: http://homeopathyusa.org/journal/ajhm-journal/ajhm-issues2017/president-s-letter.html Accessed July 10, 2017.

8. Stoppler MC. Prevacid Side Effects Center. Online document at: www .rxlist.com/prevacid-side-effects-drug-center.htm Accessed May 5, 2017.

9. Miller TC, Gerth J. Dose of confusion. ProPublica, September 20, 2013. Online document at: www.propublica.org/article/tylenol-moneil-fda-kidsdose-of-confusion Accessed July 17, 2017.

10. Borneman JP. Regulation of homeopathic drug products. Am J Health Syst Pharm 2006;63:86-91.

11. Stuck W. Homeopathic teething products pulled in U.S. still sold in Canada. The Globe and Mail, October 16, 2016.

12. Health Canada-Canada Sante. Health Product InfoWatch, November 2016. Online document at: www.hc-sc.gc.ca/dhp-mps/alt_formats/pdf/ medeff/bulletin/hpiw-ivps_2016-11-eng.pdf Accessed April 16, 2017.

13. Coward S, Lewis K. Zicam is not homeopathy! Online document at: www.naturopathic.org//content.asp?contentid=198\# Accessed June 10, 2017.

14. Fiore K. Zinc nasal sprays culprit in loss of smell. MedPage Today, July 19, 2010. Online document at: www.medpagetoday.com/primarycare/ alternativemedicine/21249 Accessed June 12, 2017.

15. Chernin D. The Complete Homeopathic Resource for Common Illnesses. Berkeley, CA: North Atlantic Books, 2006.
16. National Center for Homeopathy. [Homeopathy for] coughs and colds. Online document at: www.homeopathycenter.org/coughs-and-colds Accessed June 12, 2017.

17. Kayne L. Colds: Lee Kayne offers advice on complementary therapies for winter ailments. Online document at: www.britishhomeopathic.org/ charity/how-we-can-help/articles/babies-and-toddlers/coughs-and-sneezesspread-diseases/ Accessed June 12, 2017.

18. Donn J. Zicam not alone in side effect reports. The Associated Press, June 17, 2009.

19. Robins N. Copeland's Cure: Homeopathy and the War between Conventional and Alternative Medicine. New York: Knopf, 2005.

20. Lee WM. Acetaminophen and the US Acute Liver Failure Study Group: Lowering the risks of hepatic failure. Hepatology 2004;40:6-9.

21. Fournier JC, DeRubeis RJ, Hollon SD, et al. Antidepressant drug effects and depression severity: A patient-level meta-analysis. JAMA 2010;303: $47-53$.

22. Wittich CM, Burkle CM, Lanier WL. Ten common questions (and their answers) about off-label drug use. Mayo Clin Proc 2012;87:982990.

23. Radley DC, Finkelstein SN, Stafford RS. Off-label prescribing among office-based physicians. Arch Intern Med 2006;166:1021-1026.

24. Roy R, Tiller WA, Bell I, Hoover MR. The structure of liquid water: Novel insights from materials research; potential relevance to homeopathy. Mat Res Innovat 2005;9:577-608

25. Rao ML, Roy R, Bell IR, Hoover R. The defining role of structure (including epitaxy) in the plausibility of homeopathy. Homeopathy 2007;96: 175-182.

26. Rey L. Thermoluminescence of ultra-high dilutions of lithium chloride and sodium chloride. Physica A 2003;323;67-74.

27. Chikramane PS, Suresh AK, Bellare JR, Kane SG. Extreme homeopathic dilutions retain starting materials: A nanoparticulate perspective. Homeopathy 2010;99:231-242.

28. Bell IR. Integrative nanomedicine: Homeopathic remedies as source and silica nanoparticles acting as danger signals for nonlinear complex adaptive systems. Homeopathy 2014;103:63-64.

29. Rawlins M. De testimonio: On the evidence for decisions about the use of therapeutic interventions. Lancet 2008;372:2152-2161.

30. Angell M. The Truth About Drug Companies: How They Deceive Us and What to Do About It. New York: Random House, 2005.

31. Agency for Healthcare Research and Quality. Goal: Develop Data to Track Changes in the Health Care System. Online document at: www.ahrq.gov/cpi/about/impact/index.html Accessed October 27, 2017.

32. Patient-Centered Outcomes Research Institute [of the Comptroller General of the United States]. About our research. Online document at: www.pcori.org/research-results/about-our-research Accessed June 12, 2017.

33. Titus SL, Wells JA, Rhoades LJ. Repairing research integrity. Nature 2008;453:980-982.

34. Rossignol M, Begaud B, Engel P, et al. Impact of physician preferences for homeopathic or conventional medicines on patients with musculoskeletal disorders: Results from the EP13-MSD cohort. Pharmacoepidemiol Drug Saf 2012;21:1093-1101.

35. Rossi E, Crudeli L, Endrizzi C, Garibaldi D. Cost-benefit evaluation of homeopathic versus conventional therapy in respiratory diseases. Homeopathy $2009 ; 98: 2-10$.

36. Witt CM, Ludtke R, Mengler N, Willich SN. How healthy are chronically ill patients after eight years of homeopathic treatment? Results from a long term observational study. BMC Public Health 2008;8:413. 
37. Butehorn L. Post-acute withdrawal syndrome, relapse prevention and homeopathy. Altern Complement Ther 2017;23:228-230.

38. Kesselheim A, Avorn J, Sarpatwari A. The high cost of prescription drugs in the United States: Origins and prospects for reform. JAMA 2016;316:858871.

39. Podolsky SH. The Antibiotic Era: Reform, Resistance, and the Pursuit of a Rational Therapeutics. Baltimore, MD: Johns Hopkins University Press, 2014.

40. U.S. Department of Health and Human Services. U.S. Food and Drug Administration. Homeopathic Product Regulation: Evaluating the Food and Drug Administration's Regulatory Framework After a Quarter Century. Part 15: Public Hearing. Online document at: www.fda.gov/Drugs/NewsEvents/ ucm430539.htm Accessed August 23, 2017.

41. Jong MC, Jong MU, Baars EW. Adverse drug reactions to anthroposophic and homeopathic solutions for injection: A systematic evaluation of German pharmacovigilance databases. Pharmacoepidemiol Drug Saf 2012;21:12951301.

42. Adler UC, Paiva NM, Cesar AT, et al. Homeopathic individualized Qpotencies versus fluoxetine for moderate to severe depression: Double-blind, randomized non-inferiority trial. Evid Based Complement Alternat Med 2011;2011:520182.

43. Light DW, Lexchin J, Darrow JJ. Institutional corruption of pharmaceuticals and the myth of safe and effective drugs. J Law Med Ethics 2013;14: 590-610.

44. Eguale T. Drug, patient, and physician characteristics associated with offlabel prescribing in primary care. Arch Int Med 2012;172:781-788.

45. Weiser M, Strosser W, Klein P. Homeopathic vs conventional treatment of vertigo: A randomized double-blind controlled clinical study. Arch Otolaryng Head Neck Surg 1998;124:879-885.

46. Trichard M, Chaufferin G, Nicoloyannis N. Pharmacoeconomic comparison between homeopathic and antibiotic treatment strategies in recurrent acute rhinopharyngitis in children. Homeopathy 2005;94:3-9.

47. Jong M, Riley D, Haidvogl M. International Integrative Primary Care Outcomes Study (IIPCOS-2): Outcome of homeopathic and conventional treatment for acute respiratory and ear complaints, improving the success of homeopathy 5: A global perspective. London, January 26-27, 2006, Royal London Homeopathic Hospital.

48. Haidvogl M, Riley DS, Heger M, et al. Homeopathic and conventional treatment for acute respiratory and ear complaints: A comparative study on outcomes in the primary care setting. BMC Complement Altern Med 2007;7:7.

49. Friese KH, Kruse S, Ludtke R, Mueller H. The homoeopathic treatment of otitis media in children-Comparisons with conventional therapy. Int J Clin Pharmacol Ther 1997;35:296-301.

50. Rossi E, Crudeli L, Endrizzi C, Garibaldi D. Cost-benefit evaluation of homeopathic versus conventional therapy in respiratory diseases. Homeopathy 2009;98:2-10.

51. Bornhoft G, Wolf U, von Ammon K, et al. Effectiveness, safety and costeffectiveness of homeopathy in general practice-summarized Health Technology Assessment. Forsch Komplementarmed 2006;3:19-29.

52. Iannotti G, Melo EM. The impact of the medical speciality in primary health-care problem solving in Belo Horizonte, Brazil: Homeopaths versus family doctors: A preliminary quantitative study. Homeopathy 2012;101: $44-50$.

53. Zanasi A, Cazzato S, Mazzolini M, et al. Does additional antimicrobial treatment have a better effect on URTI cough resolution than homeopathic symptomatic therapy alone? A real-life preliminary observational study in a pediatric population. Multidiscip Respir Med 2015;10:25.

54. Sinha MN, Siddiqui VA, Nayak C, et al. Randomized controlled pilot study to compare homeopathy and conventional therapy in acute otitis media. Homeopathy 2012;101:5-12.
55. Frass M, Linkesch M, Banyai S, et al. Adjunctive homeopathic treatment in patients with severe sepsis: A randomized, double-blind, placebo-controlled trial in an ICU. Homeopathy 2011;100:95-100.

56. Frass $M$, Bundner M. Homeopathy in Intensive Care and Emergency Medicine. Kandern, Germany: Narayana-Verlag, 2016.

57. Camerlink I, Ellinger L, Bakker EJ, Lantinga EA. Homeopathy as replacement to antibiotics in the case of Escherichia coli diarrhea in neonatal piglets. Homeopathy 2010;99:57-62.

58. Albrecht H, Schutte A. Homeopathy versus antibiotics in metaphylaxis of infectious diseases: A clinical study in pig fattening and its significance to consumers. Altern Ther Health Med 1999;5:64-68.

59. Stevens M, Piepers S, De Vliegher S. Mastitis prevention and control practices and mastitis treatment strategies associated with the consumption of (critically important) antimicrobials on dairy herds in Flanders, Belgium. J Dairy Sci 2016;99:2896-2903.

60. Nauman E. Homeopathy for Epidemics: Homeopathy in Times of Crisis. Flagstaff, AZ: Light Technology Publishing, 2004.

61. Dean ME. The Trials of Homeopathy: Origins, Structure and Development. Essen, Germany: KVC Verlag, 2004.

62. Homeoprophylaxis: Human records, studies and trials. Online document at: www.homeopathycenter.org/homeoprophylaxis-human-records-studiesand-trials Accessed May 10, 2017.

63. Perko SJ. The Homeopathic Treatment of Influenza: Surviving Epidemics and Pandemics Past, Present and Future with Homeopathy. San Antonio, TX: Benchmark Homeopathic Publications 2005.

64. Bracho G, Varela E, Fernandez R, et al. Large-scale application of highlydiluted bacteria for Leptospirosis epidemic control. Homeopathy 2010; 99: $156-166$.

65. Golden I, Bracho G. A reevaluation of the effectiveness of homeoprophylaxis against leptospirosis in Cuba in 2007 and 2008. J Evid Based Complementary Altern Med 2014;19:155-160.

66. Mronisnski C, Adriano E, Mattos G. Meningococcinum: Its protective effect against meningococcal disease. Homeopathic Links 2001;14:230234.

67. Rajan A, Bagai U. Antimalarial potential of China 30 and Chelidonium 30 in combination therapy against lethal rodent malarial parasite: Plasmodium berghei. J Complement Integr Med 2013;10.

68. Bandyopadhyaya B, Das S, Sengupta M, et al. Decreased intensity of Japanese encephalitis virus infection in chick chorioallantoic membrane under influence of ultradiluted belladonna extract. Am J Infect Dis 2010;6: $24-28$.

69. Piolot M, Fagot JP, Riviere S, et al. Homeopathy in France in 2011-2012 according to reimbursements in the French national health insurance database. Fam Pract 2015;32:442-448.

70. World Health Organization. World Health Organization Assesses the World's Health Systems. Online document at: www.who.int/whr/2000/ media_centre/press_release/en/ Accessed July 17, 2017.

71. Prasad, R. Homoeopathy booming in India. Lancet 2007;370:1679-1680.

72. Clusen J, Moss S, Tournier A, et al. CORE-Hom: A powerful and exhaustive database of clinical trials in homeopathy. Homeopathy 2014;103: 219-223.

73. Tournier A. Swiss Federal Government report supports homeopathy claims. Online document at: www.hri-research.org/wp-content/uploads/2014/ 08/HRI_ResearchArticle_15_Tournier_SwissReport.pdf Accessed July 17, 2017.

74. Homeopathic Research Institute. The Swiss HTA report on homeopathy. Online document at: www.hri-research.org/resources/homeopathy-the-debate/ the-swiss-hta-report-on-homeopathy/ Accessed July 17, 2017.

75. Garrow JS. How much of orthodox medicine is evidence based? BMJ $2007 ; 335$. 
76. Dorsey ER, de Roulet J, Thompson JP, et al. Funding of US biomedical research, 2003-2008. JAMA 2010;303:137-143.

77. Shang A, Huwiler-Muntener K, Nartey L, et al. Are the clinical effects of homeopathy placebo effects? Comparative study of placebo-controlled trials of homeopathy and allopathy. Lancet 2005;366:726-732.

78. The Lancet paper by Shang et al. Homeopathy Research Institute. Online document at: www.hri-research.org/resources/homeopathy-the-debate/thelancet-paper-by-shang-et-al/ Accessed July 17, 2017.

79. Hahn RG. Homeopathy: Meta-analyses of pooled clinical data. Forsch Komplementmed 2013;20:376-381.

80. Mathie RT, Hacke D, Clausen J, et al. Randomised controlled trials of homeopathy in humans: Characterising the research journal literature for systematic review. Homeopathy 2013;102:3-24.

81. National Health and Medical Research Council [of the Australian government] Information Paper: Evidence on the effectiveness of homeopathy for treating health conditions. March 2015. Online document at: www .hri-research.org/wp-content/uploads/2015/07/NHMRC-Information-PaperMar2015.pdf Accessed July 17, 2017.

82. Executive Summary: Complaint to the Commonwealth Ombudsman regarding the NHMRC assessment of homeopathy, 2010-2015. Online document at: www.hri-research.org/wp-content/uploads/2017/04/ExecutiveSummary-to-Ombudsman-Complaint-re-NHMRC-Homeopathy-Review-FINAL .pdf Accessed October 27, 2017.
83. Davidson H. Homeopathy is bunk, study says. The Guardian, April 8, 2014. Online document at: www.theguardian.com/world/2014/apr/08/ homeopathy-is-bunk-study-says Accessed July 17, 2017.

84. Radice E, Miranda V, Bellone G. Low-doses of sequential-kineticactivated interferon- $\gamma$ enhance the ex vivo cytotoxicity of peripheral blood natural killer cells from patients with early-stage colorectal cancer. A preliminary study. Int Immunopharmacol 2014,19:66-73.

85. Saputo L, Belitsos B. A Return to Healing: Radical Healthcare Reform and the Future of Medicine. San Rafael, CA: Origin Press, 2009.

86. Zeff J, Snider P, Myers SP. A hierarchy of healing: The therapeutic order. In: Murray MT, Pizzorno J. The Encyclopedia of Natural Medicine. New York: Prima Lifestyles, 1997.

87. Schneider EC, Squires D. From last to first-Could the U.S. health care system become the best in the world? N Engl J Med 2017;377:901-904.

Burke Lennihan, RN, CCH, has been a practicing homeopath for more than 20 years and lectures on homeopathy at Massachusetts College of Pharmacy in Boston, Massachusetts, and Lesley University in Cambridge, Massachusetts.

To order reprints of this article, contact the publisher at (914) 740-2100. 